Motrivivência Ano XXII, No 34, P. 106-121 Jun./2010

DOI:10.5007/2175-8042.2010n34p106

\title{
CIBERCULTURA E EDUCAÇÃO FÍSICA: algumas considerações ontológicas
}

\author{
Fabio Zoboli' \\ Renato Izidoro da Silva²
}

\begin{abstract}
Resumo
Este trabalho é uma síntese de uma pesquisa filosófica mais ampla que versa sobre os impasses epistemológicos provocados por mudanças socioculturais hodiernas na esteira da cibercultura no âmbito esportivo dos jogos eletrônicos e da robótica e suas implicações na educação física. Definimos filosofia como justificação e significação das

questões humanas traçadas pelos limites da consciência enquanto experiência mundana de nossas implicações emergentes dos conflitos materiais das relações sociais. Assim, nosso horizonte teórico-metodológico é desenhado pelo materialismo dialético (Adorno), a ontologia (Merleau-Ponty) e a semiótica (Peirce e Lévy). Palavras-Chave: Robótica. Cibernética. Educação Física.

Abstract

This work is a synthesis of a philosophical inquiry about epistemological impasses provoked by social and cultural changes in sports cyberculture of electronic games and robotic and its implications in physical education. We define philosophy like a justification and signification of the human questions drawn by the limits of the conscience while experience of the world and the implications of the material conflicts over social relationships. So, our theoretical and methodological horizon derives from materialism dialect (Adorno), ontology (Merleau-Ponty) and the semiotics (Peirce and Lévy).

Key-Words: robotic. Cybernetic. Physical Education

1 Professor do Departamento de Educação Física da Universidade Federal de Sergipe - UFS. Doutor em Educação pela Universidade Federal da Bahia - UFBA. zobolito@gmail.com.

2 Professor do Departamento de Educação Física da Universidade Federal do Amazonas - UFAM. Doutorando em Educação pela Universidade Federal da Bahia - UFBA. Izidoro.renato@gmail.com.
\end{abstract}




\section{Introdução}

Remonta a crise paradigmática da educação física na década de 1980 a partir impasses epistemológicos provocados por mudanças socioculturais mais gerais (DA COSTA, 1999, p. 61), sendo que atualmente vemos sua provocação em especial devido ao fortalecimento da cibercultura no âmbito esportivo dos jogos eletrônicos e da robótica, o objeto principal deste ensaio. Em segundo plano, desenvolveremos reflexões sobre o lugar da educação física e de seu profissional no contexto da cibercultura, retomando as relações analógicas entre homem e máquina que já aparecera na tradição filosófica Ocidental em Aristóteles e em Descartes (SANTAELLA, 1997, p. 34)

Para tanto, pensando a filosofia como justificação e significação das questões humanas traçadas pelos limites da consciência enquanto experiência mundana pré-reflexiva (MERLEAU-PONTY, 1999, p. 1) "que nos acossa a cada um de nós diariamente", conforme Peirce (2005, p. 197), sem perder de vista que a filosofia emerge dos conflitos materiais das relações sociais em sua estrutura econômica de produção, conforme o pensamento marxista, em especial de Adorno (1973, p. 13), este trabalho é uma síntese de uma pesquisa filosófica mais ampla, acerca da influência específica da ontologia sobre a profissão, onde iremos apresentar dados sobre os tradicionais contextos pedagógicos, epistemológicos e profissionais da educação física em face da cibercultura. Ao passo que, estaremos refletindo sobre os jogos eletrônicos e a robótica enquanto formação de um novo paradigma ontológico para a educação física; que interfere diretamente na formação e na atuação do profissional da área no esporte clássico.

Nosso horizonte teóricometodológico é desenhado pelo materialismo dialético, a ontologia e a semiótica. Na interpretação de Gonçalves (1994, p. 58), para Marx a consciência "está imersa na concretude da vida corpórea e é explicada 'a partir das contradições da vida material'" (MARX apud GONÇALVES, 1994, p. 58). Ao passo que, Merleau-Ponty concebe essa íntima integração ou imersão entre sujeito e objeto, consciência e concretude na relação dialética que possibilita a interioridade ser plena das coisas e ações do mundo material, bem como este ser modelado pelas mãos do homem por meio de seu trabalho corporal e espiritual. Para Gonçalves (1994, p. 70), "Merleau-Ponty encontra afinidade com o pensamento de Marx e não vê incompatibilidade da fenomenologia existencial com o marxismo". 
A semiótica peirceana de Lévy (1998) contribui com o materialismo dialético e com a ontologia em nossa pesquisa filosófica, na medida em que, se opondo ao mentalismo e ao nominalismo, concebe o universo dos signos como material, físico e corporal: suas construções, na cultura, obedecem a regras mais analógicas que numéricas. Problematizando a emergência de representação no humano e no animal enquanto parâmetro ontológico; partimos da hipótese de não se limita a unidades simbólicas mentais. Conforme Lévy (1998), as correntes científicas dominantes em inteligência artificial, classificadas como abordagens logicistas (racionalistas) e objetivistas (empiristas) da cognição, concebem os processos cognitivos como traduções do real e da realidade por manipulações reguladas de símbolos abstratos, como no caso do conexionismo e do simbolismo. Baseados na "ideografia dinâmica", de Lévy, pensamos que as categorizações, elaborações de modelos mentais e raciocínios humanos em geral são construídos na maior parte do tempo de "modos fluidos, analógicos, metafóricos ou metonímicos e utilizam sempre em última instância intuições concretas extraídas da experiência sensóriomotora, cinestésica, social e cultural" (LÉVY, 1998, p. 214-215).

Seguiremos analisando os limites entre o atleta clássico e o ciberatleta, acrescido da presença do atleta robô tanto em estado físico quanto virtual como sendo mais um problema a ser enfrentado pela educação física no que concerne a uma reflexão mais hodierna sobre currículo. Não esquecendo que em sendo o jogo um dos objetos de estudo e de intervenção da educação física, é importante destacar que no campo da computação, segundo Epstein (1986, p. 70), a "programação de jogos em computador foi e continua sendo um setor privilegiado em pesquisa sobre IA [Inteligência Artificial]. Isto, em parte, deve-se ao fato de os jogos terem suas regras definidas com precisão, o que permite avaliar o desempenho da IA".

Sendo esse princípio comumente aplicado aos jogos esportivos que atualmente atuam tanto na cultura e economia ocidental quanto na oriental como tênis, vôlei, basquete, xadrez, lutas etc., evidenciando que o futebol, no Brasil e no mundo, é a modalidade esportiva mais desenvolvida na cibercultura, certamente graças ao valor cultural, social, político e econômico que esse esporte desempenha em quase todos os povos. Um exemplo concreto é a RoboCup, criada no Japão no ano de 1997: competição anual internacional que envolve várias modalidades, sendo que a mais popular é a RobocupSoccer ou 
Futebol de Robôs, cuja finalidade é o desenvolvimento científico e mercadológico competitivo das novas tecnologias computacionais.

\section{Contexto pedagógico, epis- temológico e profissional da educação física}

A partir da década de 80 do século $X X$ se tornou lugar comum refletir sobre certa crise no contexto pedagógico e epistemológico da educação física. Basicamente, essa última pode ser demarcada por alguns momentos mais significativos historiograficamente. Podemos compreender sua constituição praxeológica segundo orientações antropológicas, sociológicas, culturais, políticas, econômicas e filosóficas provindas de outros campos sociais tais como a medicina, o nacionalismo, o capitalismo e a moral enquanto agentes de criação da humanidade moderna, cujos principais meios foram: o higienismo, a alfabetização, a ginástica e bem posteriormente, elemento que mais nos importará aqui, o esporte. A crise em questão implica a dúvida sobre qual seria exatamente ou cientificamente o objeto, a metodologia e o objetivo da educação física.

Inevitavelmente, esse horizonte teórico-metodológico que coloca a física-corporal como elemento fundamental das construções humanas acaba levantando muitas perguntas/respostas à educação física. Dentre algumas destacamos: seu objeto seria o corpo biológico e seu método a ginástica científica, com o fim de atingir a saúde ? Teríamos como objeto a atividade física cuja metodologia estaria nos exercícios físicos amparados pelos estudos da fisiologia do exercício, tendo como objetivo também promover a saúde? Sendo seu objeto o movimento corporal humano investigado pela cinesiologia, restaria compreender as dimensões físicas do movimento para melhor formular uma pedagogia? A motricidade humana entendida como o objeto exato, não estaríamos colocando a educação física como um campo metodológico por onde se alcançaria a transcendência humana? Tendo a cultura corporal como um possível objeto de estudo e atuação, sua metodologia seria a identificação ou formulação de problemas (contradições) sociais e politicamente contextualizados em suas execuções, tendo como objetivo a consciência sobre a situação do sujeito através da vivência do corpo e do movimento enquanto manifestação histórico-cultural? Por fim, tomando o esporte como seu objeto, a finalidade da educação física seria a de desenvolvem metodologias de treinamento desportivo (aptidão 
física, técnica e tática) objetivando a formação do atleta?

Como bem sabemos, não há dentre tais perspectivas alguma que seja a mais correta e verdadeira, bem como a mais aplicável e exequível. O que importa apontarmos enquanto diferença em relação à cibercultura esportiva e o esporte robótico é que as perspectivas apresentadas pressupõem alguns elementos ontológicos desafiando ou inovando sobre os princípios filogenéticos: o homem ou a mulher humano, o corpo e o movimento produtivo: o jogo, a luta, o esporte, a dança, o trabalho, o descanso, o lazer, a tecnologia, a prótese etc. Em suma, para a educação física sempre esteve em prática o ser humano enquanto corpo ou possuidor de um, que de alguma forma se movimenta estando e fazendo parte do mundo natural e social. Em termos mais práticos, a educação física não tem existido sem que uma entidade corporal humana como única e exclusiva realizadora de algum movimento que inevitavelmente é produto e produtor da cultura, e que assim ele se realiza enquanto ser solitário e social. Principalmente no Brasil, sabemos que a prática da educação física escolar e popular, com algumas exceções, tem se pautado na prática corporal dos esportes modernos em geral, só que na sua forma jogada.
Diante disso, temos de pensar que a crise da década de 1980 na educação física foi gerada no contexto histórico, social, cultural e econômico em que o corpo humano em movimento é evento central das expressões e realizações materiais humanas: o jogo, o trabaIho, o descanso, o sexo, a guerra etc. Sendo que os questionamentos daí em diante podem ser reportados às clássicas dúvidas antropo-filosóficas em que o homem é objeto central no que concerne ao seu espírito e ao seu corpo, sob uma história da educação física em que corpo e movimento foram descritos e concebidos de acordo com o paradigma da dualidade corpo-mente. Partindo do platonismo, passando pela dicotomia cristã, chegando ao dualismo radical de Descartes, desembocamos finalmente no modelo de corpo anátomo-fisiológico da medicina. Os pensadores da educação física da década de 1980 , por influência do marxismo, do freudismo, da fenomenologia, dos ideais democráticos, da própria crise do modelo médico de homem fincado nas Ciências Naturais e a própria emergência da robótica ao lado da genética trazem à tona perguntas como: o que é o corpo, o movimento, o homem? Afinal, o que é a educação física? Inevitavelmente, emerge um corpo humano material que se 
movimenta social, histórica, econômica, política e culturalmente. Pegando principalmente a temática do trabalho, da educação e do esporte, o bem-estar corporal é visto como determinado não apenas pela mecânica anátomo-fisiológica do corpo, mas principalmente pela mecânica social, sendo que não adiantaria melhorar a primeira sem transformar a segunda e viceversa. Assim, trabalho, educação e esporte transcendem seus espaços imediatos, para serem tratados indiretamente no campo dos manejos racionais e lógicos do pensamento enquanto aprisionamento do mundano na forma de ideias segundo suas estruturações políticas, sociais, econômicas que têm como objeto central o corpo e seus movimentos que produz tanto realidade material quanto realidade simbólica e imaginária vinculada à algum projeto de humanidade.

No contexto do capitalismo contemporâneo esse esquema se faz mais notável de modo que toda e qualquer proposta de movimento para o corpo, não visa outra coisa senão produção e consumo de mais capital material, simbólico e imaginário, onde o corpo é receptor e desperdiçador final de energia. Para longe de qualquer esquema mental e intelectual superior, todos, "gênios" e "ignorantes", "críticos" e "alienados", têm ou são um corpo que passa a se realizar no movimento de consumo que resulta na produção e realização do ser segundo estéticas corporais na presença e existência corporal que desperdiça energia nos exercícios vazios das academias de ginásticas como sendo robôs que consomem energia sem transformá-la. Como afirma Contrera (2002, p. 60), "o corpo é o primeiro e o último reduto da experiência humana".

Diante de tal problemática, os pensadores da educação física oscilaram entre resolver essas questões no âmbito teórico-epistemológico e/ou práticopedagógicos da educação física. Foram construídos alguns sistemas filosóficos na tentativa de orientar a prática pedagógica dos professores. Também foram pensadas muitas metodologias cientificas para resolver problemas de cunho procedimental investigativo, aplicativo e organizacional, fazendo com que, curiosamente, a educação física passasse a conviver com elaborações mais que abstratas, destinadas a questões mais que triviais, como é próprio da ciência moderna, segundo Bachelard (1996, p. 7).

Entretanto, os professores não puderam abandonar seus empregos nas escolas públicas e privadas, as já decadentes quadras poliesportivas a céu aberto; seu bom, velho e útil apito, o indispensável 
boné (alguns, o protetor solar), sua sensação de lazer nas aulas não diretivas facilitadas pela autonomia dos estudantes gerada pela maior paixão brasileira, o futebol; tendo em troca o gozo enfadonhas discussões puramente filosóficas, epistemológicas e antropológicas, no caso do Brasil. De fato, a crise epistemológica e pedagógica de 1980, aliada ao banho de Sol diário que a maior parte dos professores tem de tomar nas quadras a céu aberto, serviu para "esquentar" a cabeça e os neurônios de muitos.

Bracht (2003, p. 30) localiza o início desse processo nas décadas de 60 e 70 do século XX devido ao desenvolvimento, no contexto da educação física, das tradicionais disciplinas científicas como fisiologia, anatomia, psicologia, física, sociologia em suas especificidades: fisiologia do esforço, biomecânica, psicologia do esporte, a sociologia do esporte etc., bem como podemos acrescentar a aprendizagem e desenvolvimento motor, antropometria, sociologia do lazer, pedagogia do esporte, psicomotricidade etc. $\mathrm{O}$ autor ainda argumenta que a incorporação de práticas científicas pelo campo acadêmico da educação física "determinou a criação de entidades científicas próprias, realização de eventos científicos próprios, criação de cursos de pósgraduação, [...] programas de apoio à pesquisa [...]" (BRACHT, 2003, p.
30). Ainda, para além das subdisciplinas científicas, esse movimento motivou a construção de novos sistemas científicos como a Ciência da Motricidade Humana ou Ciência do Movimento Humano.

Como se tais problemas não bastassem; a educação física, ainda que resistindo saber, tem passado por uma crise paradigmática ainda mais profunda e curiosa, que é da ordem de uma nova e outra ontologia, questionadora dos antigos parâmetros filogenéticos deterministas. Da Costa (1999, p. 61) traz contemporaneamente como "primeira distinção conceitual e também um primeiro conflito sociocultural [o] descompasso entre a inovação tecnológica e o conhecimento profissional, que cria uma oposição entre a demanda social de profissionais atualizados e a formação pouco renovada destes profissionais".

Na esteira de uma pesquisa filosófica sobre ontologia; se o corpo em movimento em suas várias dimensões humanas de sua presença física foi o mote das reflexões no final do século $X X$, tudo indica que grande número de corpos em movimento não mais deseja estar nas quadras descobertas ouvindo os gritos e os apitos dos professores. As revoluções sociais, culturais e econômicas provocada pelo advento das novas 
tecnologias; também conhecidas como promotoras da cibercultura, têm questionado o corpo clássico da educação física, na medida em que os jogos eletrônicos deslocam a realização das expressões corporais dos sujeitos humanos arquitetada para o exercício de grandes grupos musculares em movimentos vigorosos, para o âmbito das realidades virtuais enquanto objetos matemáticos consumidos em seus modos de interface visual.

Em outros termos, aqueles que podemos chamar de ciberatletas trocaram ou deslocaram a realização de seus movimentos integrais do corpo próprio no esporte clássico, onde pressupõem a ação dos grandes grupos musculares, pelos movimentos limitados à habilidade da coordenação motora fina na operação do joystick que envolvem no máximo a coordenação óculo manual. Os micro-gestos manuais ligados ao joystick se tornam pantomima perfeita para a fabricação de expressividades corporais impossíveis ao corpo humano, ou ao menos impossível para a maioria dos sedentários portadores de inúmeros sintomas hipocinéticos, levando-nos a perguntar, no fim de contas, quem é, afinal, o atleta: o operador ou a máquina? Sobre isso, Da Gama (2005, p. 174), pautado nas pesquisas de Heim acerca das desordens perceptivas provocadas por intensificações de vivência em ambientes virtuais, argumenta que nosso atual paradigma de movimento corporal precisará ser reformulado. "Isto porque ao alterarem a homeostase do corpo pelo envolvimento com simulações imagéticas, estes dispositivos abrem um precedente para que metamorfoses metabólicas ocorram com pouca ou nenhuma solicitação motora do aparelho locomotor".

Para os mais antropocêntricos que se deixam enganar pelas pequenas ações humanas no interior de um universo físico-químico cheio de possibilidades próprias e oferecido ao nosso mínimo esforço, a resposta à nossa pergunta será: o atleta é o operador da máquina. Contudo, um olhar mais atento pode mostrar uma interação entre máquina e jogador, na medida em que a primeira estrutura, opera, possibilita e muitas vezes condiciona ações do segundo. Em termos estruturais, podemos pensar a ação intencional e analógica da máquina construindo operações semióticas no jogador, desde sua ergonomia, aos comandos de hardware sobre o software que produz seu efeito de pantomima sobre pantomima: das mãos ao hardware, deste ao software, até a produção das imagens virtuais do jogo que retornam sobre o jogador pela visão, pelo tato e pela audição, cujo aprendizado 
não é dos movimentos corporais expressos pelos atletas virtuais na tela do jogo eletrônico, mas sim da coordenação motora fina daquele que manipura o controle remoto.

O treino do ciberatleta, portanto, ao modo industrial de operar o mundo, se limita à melhora da habilidade laboral manual com o joystick, acompanhada da necessária compreensão ou incorporação da lógica estrutural do jogo expressa nas ações dos atletas virtuais; desfazendo o velho paradigma positivista que pensa a construção do conhecimento mediante a dicotomia entre sujeito e objeto, em direção a uma indistinção gnosiológica, arqueológica, epistemológica, técnica e tecnológica entre sujeito e objeto. Portanto, conforme Da Gama (2005, p. 171), "as imagens computadorizadas não são entidades absolutamente acabadas; com elas consegue-se estabelecer um circuito dialógico aberto". Um exemplo disso, o relato de Ascott (1997, p. 336): "Cada fibra, cada nó, cada servidor da Net é parte de mim. À medida que interajo com a rede, reconfiguro a mim mesmo".

\section{Ciberatletas, atletas virtuais e atletas robôs: a utopia dos atletas clássicos}

Do nosso ponto de vista, não somente a máquina é uma tecnologia do humano, sendo este uma tecnologia da máquina, de modo que esta estende suas dimensões, possibilidades e reformulações mediante o uso humano: o homem é uma extensão da máquina no sentido de sua realização enquanto ser máquina. Essas novas materialidades do corpo, na visão de Fraga (2004, p. 63), estão imbricadas ao corpo vivido e não apenas percebido e visto pelo outro, mas fundamentalmente como a tecnologia investe energia e interesse no corpo humano a fim de se realizar. Da Gama (2005, p. 165), semeIhante a Mattelart, menciona a cibercultura como uma incorporação de linguagens e equipamentos da computação eletrônica no cotidiano das pessoas. Significa dizer que o poder ontológico da tecnologia de construir a humanidade do homem, principalmente quando do escopo de seu crescente alcance, passa a traçar as fronteiras da cibercultura que pouco a pouco vêm atuando sobre o campo dos esportes, jogos e práticas lúdicas. Temática, conforme Da Gama (2005, p. 165), que vem sendo abordada em estudos recentes realizados por Betti, 1998 e Feres Neto, 2001.

Assim, a concretude físicocorporal não serve para divagarmos por infinitas possibilidades, mas sim por possibilidades entremeando seu contrário, as impossibilidades: os 
limites estruturais dos lugares e dos corpos, que não sendo estruturas fixas e eternas, têm suas temporalidades e espacialidades ontológicas lançadas na esteira do devir da história movimentada por interesses energéticos. Portanto, o esporte clássico se realiza na fenomenologia do jogador que se expressa integralmente no interior de regras físicas bem gerais, enquanto o acervo motor do atleta virtual especializado na relação com o espaço restrito à ação, se realiza a partir da atividade pensante do ciberatleta segundo sua psicomotricidade que induz o joystick a a transferir impulsos codificados aos atletas virtuais a fim de que esses tracem uma pantomima de movimentos em si mesmos sem significados e sem relação análoga com qualquer outro tipo de movimento existente nas práticas corporais tradicionais.

Por outro lado, as expressões de pantomima dos jogos eletrônicos são incomparavelmente mais espetaculares, no plano do impossível corporal, em face dos movimentos corporais reais dos atletas clássicos. Realidade que possibilita o ciberatleta se realizar nos movimentos do atleta virtual, e esse nos movimentos manuais discretos do jogador: possuidor de uma programação prévia e independente do primeiro. Podendo, portanto, ser assemelhado ao atleta clássico, que sujeito a estruturas anátomo-fisiológicas e lógicas (metafísicas, virtuais ou subjetivas), tem suas ações (menos espetaculares) como resultado de uma interação com o campo de jogo e seus limites e regras, além do simbolismo e imaginário social que o programam, evidentemente, de maneira tão complexa quanto os virtualismos eletrônicos.

Nessa relação, o ciberatleta pode ser substituído pela figura do torcedor que com seus gritos e palavras de ordem em meio à torcida tenta produzir, com menos eficácia, mas com algumas estratégias e mandingas míticas e ritualísticas, um controle pantomímico e analógico sobre os atletas clássicos em campo. Em certo sentido, torcedor, atleta e ciberatleta investem esforços físicos na tentativa de governar um sistema programático ingovernável, o jogo como cinemática do devir em relação ao qual o observador busca desvendar compreender sua dinâmica com o fim de manipular suas forças volitivas enquanto variáveis dinâmicas.

Está em pauta uma questão ontológica historicamente crucial para os educadores físicos: a cibernética, isto é, a arte de governar a partir do preceito baconiano de que "saber é poder". Segundo Epstein (1986, p. 6-7), seguindo a interpretação de Norbert Wiener, "a origem grega do termo remonta a Platão, 
que emprega $\chi \nu \beta \varepsilon \rho v \eta \tau \imath \chi \eta^{\prime}$ como a arte de pilotar navios (Górgias 511 e Político 299) e, em sentido mais amplo, a arte de governar o Estado". Na robótica, a cibernética se torna o grande desafio, já que como seria possível construir um robô capaz de governar a si próprio segundo leis e finalidades humanas? Em outros termos, aí está implicada a arte de educar ao lado da arte de governar: só um ser educado tem a capacidade de governar, e é somente sendo governado que o sujeito tem condições de ser educado. Inevitavelmente, a dialética entre governo e educação acaba por gerar a noção de currículo, isto é, de caminho ou destino, da mesma forma que o comandante de um barco tem como tarefa, justamente, cursar um caminho. De modo que, isso apenas é possível se ele governar o barco em relação ao devir da água. Para isso, o sujeito deve ter sido bem educado no sentido de governar a si próprio, suas volições negativas e positivas.

Vemos isso em Kant (2004, p. 21) quando disserta sobre a pedagogia: "Entre as descobertas humanas há duas dificílimas, e são: a arte de governar os homens e a arte de educá-los". Isso significa que a cibernética na robótica não passa de uma transferência da noção de governo e educação das crianças, dos escravos e dos trabalhadores. Kant (2004, p. 37), por exemplo, ao falar da educação física, menciona: "Ainda que alguém que tome a seu cargo uma educação, como governante, não receba de imediato as crianças, quando então deveria ocupar-se também da sua educação física [...]". Nas palavras de Soares (2004, p. 111): "Com sua materialidade, o corpo educado pela matéria da qual é feito o mundo, circunscreve um retrato da sociedade [...]". Ou, nas palavras do cineasta Pasolini, citado pela mesma autora: "A condição social se reconhece na carne de um indivíduo... Porque ele foi fisicamente plasmado justamente pela educação física da matéria da qual é feito o mundo" (apud SOARES, 2004, p. 110).

Nesse sentido, tanto na robótica quanto na pedagogia, o problema central está em como educar a matéria inicialmente sem forma e sem finalidade. A partir desse questionamento, podemos dizer que a educação física emerge na modernidade justamente pela limitação paradigmática espiritualista e mentalista da pedagogia e da ideologia, cujos fracassos resultaram na intensificação do controle material, do poder e do medo investidos sobre a física-corporal dos sujeitos no interior das instituições educativas: uma das temáticas preferidas de Foucault (2007).

Não obstante, a cibernética atrelada à educação pedagógica e ao governo político, como é próprio da 
Modernidade, levanta uma série de preocupações da parte do sujeito em relação ao objeto. O aprendiz, até então objeto da pedagogia, dos professores e dos patrões, atualmente emerge violentamente enquanto sujeito de desejo, de amor e de ódio, o que acaba por amedrontar a lógica disciplinar da escola e da fábrica. Assim, o fracasso do aprendiz é interpretado como sendo consequência da falta de competência governamental do poder público e da autoridade dos professores, bem como da noção de não-governabilidade natural dos alunos muitas vezes conceituados como selvagens. Medo, educação e governo andam lado a lado, pois aí se coloca como pano de fundo a prática do controle, do poder e da ordem ideológica sobre a matéria-corporal. Em nossa época essa relação é transferida para a robótica, na medida em que, assim como aluno, trata-se de um processo de criação enquanto fruto da ação artesanal, industrial ou modeladora da educação como formação/preparação (aluno) e programação (robô) para vida funcional e pragmática em sociedade. Asimov $(2007$, p. 7$)$ alerta sobre a relação entre o medo e o avanço da robótica em muitos de seus romances, como por exemplo, em $O$ feitiço e o feiticeiro, de Ambrose Bierce, que conta a história de um inventor solitário, Moxon, cuja invenção não conseguiu controlar, não retomando outra estória genial senão a do Doutor Franckenintein.

Dessa forma, mais uma vez os profissionais da educação física são inseridos em uma nova crise, mas, ainda sobre um velho paradigma, de modo que presenciam dois de seus principais objetos de estudo e atuação, o corpo em movimento e o esporte, escaparem às suas epistemologias e pedagogias historicamente limitadas pela dicotomia entre corpo e mente, corpo e ideologia que vem comandando as intervenções de controle e poder sobre os alunos e atletas clássicos.

Evidencia-se, mais uma vez, que o motivo da crise da educação física se origina justamente da impossibilidade de tomar o corpo em movimento e o esporte como objetos exclusivos de suas reflexões, pois ambos se aproximam mais de uma natureza pública (Estado), mundana (popular) e inter e multidisciplinar (acadêmica) no contexto do capitalismo. Para Lovisolo (apud DA COSTA, 1999, p. 58) a educação física se contrapõe à sua situação atual irrevogável própria das profissões da área da saúde: o pluralismo. Assim, esse desejo de controle e monopólio das práticas corporais por parte da educação física se tornou justamente o ponto de inviável confusão epistemológica da profissional, segundo Bracht (apud DA COSTA, 1999, p. 56). 
O corpo em movimento e o esporte, que também têm sido objetos de interesse da filosofia, da antropologia, da sociologia, da psicologia, da biologia, da física etc., atualmente emerge de maneira independente no contexto da ciência da computação, em relação às quais os atuais currículos de graduação da educação física se mostram limitados e distantes, ainda preocupados com cibernéticas escolásticas e militares. Situação que poderá motivar infindas discussões epistemológicas e de mercado acerca do lugar e da competência cibernética do profissional de educação física nesse novo contexto de produção material e subjetiva, ao lado das desgastadas discussões sobre as clássicas fronteiras profissionais concernentes a profissões como a fisioterapia, a enfermagem, a medicina, a pedagogia, enquanto que as ciências da computação vêm, sem pedir licença, atravessando todos esses campos de um modo que vem possibilitado apender e ensinar.

Com isso apontamos que a grave questão ontológica surgida dos tênues limites entre ciberatletas, atletas virtuais, atletas clássicos, deverá motivar perguntas como: em quais desses atores o profissional da educação física poderá centrar suas atenções? Será que ele se limitará a realizar atividades físicas laborais aos ciberatletas que certamente desenvolverão Lesões por Esforço Repetitivo (LER)? Sendo que, essa questão se apresenta como possível, à medida que, como vimos acima ainda de modo elementar, tanto ciberatleta quanto o atleta virtual necessitam de alguma espécie de programação, ponto que permite o profissional da educação física atuar na esfera cibernética e não apenas na esfera da reprodução e da recuperação. O primeiro através de treinamentos em ambientes de aprendizagem clássicos e o segundo por meio de programações computacionais algorítmicas ou conforme regras heurísticas.

Mais ainda podemos considerar em que medida a experiência histórica da educação física no âmbito do esporte clássico, pode contribuir com a programaçãol treinamento dos ciberatletas e dos atletas virtuais. Sobre isso, podemos garantir que seria de grande importância estudos na área da ergonomia, da biomecânica, da cinesiologia, da cultura corporal, da ontologia, da pedagogia do esporte, no que concerne tanto ao desempenho do ciberatleta quanto na programação do atleta virtual e dos atletas robô, já que, no caso destes últimos, sendo menos óbvio pensar, seus movimentos são pautados nos movimentos corporais humanos enquanto base para suas espetacularizações transcendentes. 
Nas palavras de Santaella (1997, p. 35), essa lógica esteve na "base das primeiras noções de robô, máquina à imagem e semelhança dos músculos humanos, pronta para trabalhar para o homem ou em seu lugar". Não esquecendo da intenção da diminuição das inconstâncias que leva ao erro.

\section{Considerações finais}

Não cabe seguirmos aqui com descrições mais detalhadas sobre a realidade ontológica dos ciberatletas, atletas virtuais, dos atletas robôs e dos atletas clássicos. Portanto, encerramos este trabalho de síntese apresentando um termo razoável sobre as relações entre os mesmos, enquanto possíveis parâmetros ontológicos de compreensão para os profissionais da educação física no sentido de considerar tal temática nos currículos de formação nos cursos superiores da área. Como bem disse Fraga (2004, p. 64), "o campo esportivo construiu sua visão particular sobre o início da era 2000 como um tempo de mudanças, de materialização de vários investimentos científicos e tecnológicos, que resultariam em outra condição física". Contudo, Fraga está mais atrelada ao imaginário acerca do ciborg, tal como Manuel Sérgio (2003, p. 56), no que implica seu desenvolvimento pela biotecnologia; enquanto nós optamos refletir às voltas da robóti$\mathrm{ca}$, o que não diminui, em qualquer um dos pontos de vista, o caráter obsoleto dos atuais currículos da educação física.

Não se trata de reivindicar, para a educação física, o monopólio das práticas corporais no contexto da cibercultura. Este trabalho pretende veicular um sentido em relação ao qual a educação física não pode se atrasar e nem tentar recuperar o tempo perdido por meio de compreensões verticais acerca de currículos prescritos cujos conteúdos não fazem, em grande parte, sentido àqueles que realmente podem ser chamados de consumidores finais. $\mathrm{O}$ caráter pluralista do corpo humano e de seus movimentos, sugerem que a educação física acesse à realidade das novas tecnologias de maneira horizontal conhecendo e reconhecendo seus vínculos epistemológicos e profissionais com o esporte em suas modalidades na cibercultura.

Sugerimos que esse caminho possa ser iniciado pelo reconhecimento de que a ontologia dos ciberatletas, dos atletas virtuais, dos atletas robôs físicos emergem como extensão da lógica social, cultural e econômica do atleta clássico: a) o fato de a cibercultura ter gerado o ciberesporte segundo modelos institucionais clássicos: federações, confederações, 
associações, equipes, clubes etc., impede qualquer tentativa de subjugar tal prática ao status de puro entretenimento e b) a análise filosófica que realizamos sobre a ontologia do ciberesporte e do esporte clássico sugere a impossibilidade epistemológica de considerar os atletas virtuais e os atletas robôs como simples máquinas absolutamente sem autonomia e sem intencionalidades produzidas pelas relações sociais materiai com os ciberatletas e com os atletas clássicos.

\section{Referências}

ADORNO, Theodor W.; HORKHEIMER, Max. Temas básicos da sociologia. Tradução de Álvaro Cabral. São Paulo: Cultrix, EDUSP: 1973.

ASCOTT, Roy. Cultivando o hipercórtex. In: A arte no século XXI: a humanização das tecnologias. Diana Domingues (org.). São Paulo: Editora da UNESP, 1997.

BACHELARD, Gaston. A formação do espírito científico: contribuição para uma psicanálise do conhecimento. Tradução de Estela dos Santos Abreu. Rio de Janeiro: Contraponto, 1996.

CONTRERA, Malena Segura. A mídia eletrônica e a "abolição do corpo". In: Mídia e pânico: saturação da informação, violência e crise da cultura. São Paulo: Annablume, 2002.

DA COSTA, Lamartine P. Formação profissional em educação física, esporte e lazer no Brasil: memória, diagnóstico e perspectivas. Blemenau: Ed. FURB, 1999.

DA GAMA, Dirceu Ribeiro Nogueira. Ciberatletas, cibercultura e jogos digitais: considerações epistemológicas. In: Revista Brasileira de Ciências do Esporte, v. 26, n. 2, p. 163177, jan. 2005.

EPSTEIN, Isaac. Cibernética. São Paulo: Editora Ática, 1986.

FOUCAULT, Michel. Vigiar e punir: história das violências nas prisões. $33^{\mathrm{a}}$ ed. Petrópolis, RJ: Vozes, 2007.

FRAGA, Alex Branco. Anatomias emergentes e o bug muscular: pedagogias do corpo no limiar do século XXI. In: Corpo e história. Carmen Lúcia Soares (org.). Campinas, SP: Autores Associados, 2004. (Coleção educação contemporânea).

GONÇALVES, Maria Augusta Salim. Sentir, pensar, agir: corporeidade e educação. Campinas, SP: Papirus, 1994.

HISTÓRIAS DE ROBÔS. Isaac Asimov (org.). Tradução de Milton Persson. Porto Alegre: L\&PM, 2007. (Coleção L\&PM Pocket). 
KANT, Immanuel. Sobrea pedagogia. Tradução de Francisco Cock Fontanella. $4^{\mathrm{a}} \mathrm{ed}$. Piracicaba: Editora UNIMEP, 2004.

LÉVY, Pierre. A ideografia dinâmica: rumo a uma imaginação artificial? São Paulo: Edições Loyola, 1998.

MERLEAU-PONTY, Maurice. Fenomenologia da percepção. Tradução de Carlos Alberto Ribeiro de Moura. $2^{\text {a }}$ ed. São Paulo: Martins Fontes, 1999. (Tópicos).

PEIRCE, Charles Sanders. Semiótica. Tradução de José Teixeira Coelho Neto. São Paulo: Perspectiva, 2005. (Coleção Estudos).

ROSÁRIO, João Maurício. Princípios de mecatrônica. São Paulo: Prentice Hall, 2005.

SÉRGIO, Manuel. Alguns olhares sobre o corpo. Coleção: epistemologia e sociedade. Lisboa - Portugal: Instituto Piaget, 2003.
SANTAELLA, Lucia. O homem e as máquinas. In: A arte nos século XXI: a humanização das tecnologias. Diana Domingues (org.). São Paulo: Editora da UNESP, 1997.

SOARES, Carmen Lúcia. Corpo, conhecimento e educação: notas esparsas. In: Corpo e história. Carmen Lúcia Soares (org.). Campinas, SP: Autores Associados, 2004. (Coleção educação contemporânea).

STELARC. Das estratégias psicológicas às ciberestratégias: a protética, a robótica e a existência remota. In: A arte no século XXI: a humanização das tecnologias. Diana Domingues (org.). São Paulo: Editora da UNESP, 1997.

Recebido: julho/2010. Aprovado: outubro/2010. 